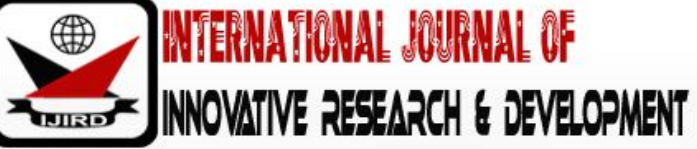

ISSN 2278 - 0211 (Online)

\section{Perceptions of Students on the Fairness of Formative and Summative Assessments in Tanzanian Universities}

\author{
Paul Raphael Kitula \\ Ph.D. Candidate, Mwenge Catholic University, Tanzania \\ Dr. Moses Gadi Koda \\ Lecturer, Mwenge Catholic University, Tanzania
}

\begin{abstract}
:
This study was conducted to assess the perception of university students on the fairness of formative and summative assessments conducted in Tanzanian universities. The study was guided by two specific objectives which aimed at finding out the perceptions of students on fairness of formative and summative assessments and identifying the sources of errors in assessment. The researcher adopted a cross sectional design which enabled them collect data from study respondents at one time. Third year students from universities offering teacher education in Tanzania were targeted whereby stratified sampling technique was used to obtain the study sample which consisted of 336 students selected from four universities. Questionnaires with open and closed ended questions were used to collect data and the collected data were analyzed descriptively in frequencies, percentages, means and standard deviations and the hypothesis were tested using independent sample t-test and one-way ANOVA. The study found students not to be well satisfied with the general assessment procedure; both formative and summative assessments were found to have the same level of fairness which was satisfactory. Moreover, lecturer, tools, and condition related factors were found to contribute to unfairness at the same basis. Lecturers in public universities were found to be favoring their students more than the ones in private universities. The study recommended universities to design and implement appropriate procedures so as to improve fairness in assessments.
\end{abstract}

Keywords: Perception, assessment, fairness, validity

\section{Introduction and Problem Statement}

The standards for teacher competence in educational assessment (1999) require educators to be skilled in recognizing unethical, illegal inappropriate assessment methods and uses of assessment information (Linn and Gronlund, 2000). This standard calls for fair assessment as indicated by Linn and Gronlund (2000) that fairness should be maintained in all assessment activities from the planning, administration and interpretation of the obtained results. Fairness is an indication of validity whereas the use of an assessment procedure that leads to unfair treatment of the subjects is considered not to be valid. This is further supported by Aiken (2000) who documented that the fairness of an assessment tool must be demonstrated for it to give results that will allow valid interpretation. Therefore, it is the responsibility for those who develop assessment tasks to ensure that the developed tasks are as free as possible from bias (NCME, 1995).

Despite of fairness being one of the basic components of high quality assessment, Raisanen, Tuononen, Postareff, Hailikari \& Virtanen (2016) found problems in assessment fairness in a biochemical course at the University of Helsinki in Finland where teachers were reported to assess different level of understanding than what was intended. A good assessment procedure should have an acceptable level of difficulty that is according to the levels of the learners. It should not be too difficult or too easy for it to give results that will allow the making of valid inferences. If the assessment tasks are too difficult or measuring different abilities than what has been indicated in the course outlines as found by Raisanen et al (2016), it will not allow students to maximally demonstrate their potentialities in the assessed areas.

A study conducted in Portugal by Pereira, Flores and Barros (2017) found out students to consider assessment tasks that are learner centered to be fairer than teacher dominated ones. These findings suggest that students consider their lecturers to be unfair in assessment. The findings by Pereira et al (2017) are theoretically supported by Popham (2008) who identified three types of errors that may result due to lecturer's bias. The first error is generosity error whereby lecturers end at giving students higher scores that what they actually diverse. The second one is severity error whereby a lecturer does not think if a student can produce a quality work and therefore he ends at giving lower scores than what as actually disserved and the third error is the central tendency error whereby lecturers avoid giving either too high or too low scores to students but do grade them as average performers. All these errors may affect fairness of the assessment procedure.

Farness in assessment calls for the elimination of all features that may either elevate or lower the score that a student gets apart from his ability and understanding on the tested contents. One of these features is cheating whereby 
more than $50 \%$ of both lecturers and students at Hawassa University in Ethiopia indicated to have always experienced cheating incidences (Bachore, 2016). Lack of clear policies, tests being too difficult and pressure to get good grades were found to be the major reasons for students to be engaged in cheating (Bachore, 2016). When a test is too difficult, students will see it as being harmful rather than helpful and therefore may be encouraged to cheat so as to secure good grades (Linn and Gronlund, 2000; Bachore, 2016). Cheating incidences make assessment practices not to be fair as the students who do not cheat will receive low grades than the one who cheated. Therefore, the results that are affected by cheating may not be useful in making accurate inferences concerning students' learning. Therefore, this study was conducted to determine what students perceive about the fairness of assessment practices in universities in Tanzania where such study had not been conducted before.

\section{Theoretical Framew ork}

This study was guided by the classical test theory (CTT) developed by Lord and Novic in 1968. According to the theory, a persons' observed score on a given measure is composed of a true score and an error score. An observed score is the one that a person gets on an assessment task while the true score is considered to be the true ability of a person which is assumed to be constant for a particular person. An error score on the other hand refers to anything that may affect persons' performance on a particular test

It is emphasized by Aiken (2000) that a person's true score can never be determined exactly; it must be estimated from the person's observed score (Aiken, 2000 84). Assuming that the measurement errors are maintained at a minimum effect, the value of true score will be improved. Improving the value of the true the score makes the results a student gets on a given assessment task represent his or her true ability in the assessed areas. This will make the stakeholders to judge the competence of graduates based on their assessment results whereby graduates with high scores will be expected to demonstrate higher competencies as compared to those with low scores.

Through ascertaining that each observed score is composed of errors, the theory creates awareness to the researchers that scores that graduates have on their certificates may not necessarily reflect their true abilities. Therefore, it is possible to find a graduate teacher with good grades but failing to defend such good performance in the place of work. It is therefore important for developers of assessment tasks in universities to put more efforts in making sure that the results that students get out of assessment tasks are having minimal errors as possible for them to be effectively used to infer the possession of skills and knowledge. Otherwise, if the error scores are very high than true scores, then the observed scores may not meaningfully represent the true abilities of teacher trainees in the assessed areas and hence the inferences made may not be appropriate. The researchers in the current study therefore investigated the sources of errors in measurements and assessed the effect of each to the fairness of assessments.

\subsection{General Objective}

The general objective of this study was to assess the perceptions of university students on the fairness of assessment practices in Tanzanian universities.

\subsection{Specific Objectives}

- To determine students' perceptions on fairness of formative and summative assessments.

- To investigate the sources of unfairness in assessments.

\section{Methodology}

The study adopted a cross sectional design which allowed them to collect data from different respondents in one time. The target population for the study included third year students from universities offering teacher education in Tanzanian. The study sample therefore consisted of 336 students who were selected using stratified sampling on the basis of gender from two public and private universities. Questionnaires were used to collect data from students. These tools were firstly pilot tested into two universities (private and public) and modified to suit the intended purpose. Content validation was done through the use of experts in the field of research and assessment to check language clarity and whether the tools adequately addressed the objectives. Comments from the experts were incorporated to improve the tools.

The collected data were analyzed both descriptively and inferentially. Descriptive analysis included organizing the data into frequency, percentage and means. Inferential analysis on the other side included the use of independent sample t-test and one-way ANOVA. Results of analysis were presented using tables.

\section{Findings}

\subsection{Fairness between Formative and Summative Assessments}

The first objective aimed at finding out the perceptions of university students on the fairness of assessments in universities. The researchers asked students to compare the fairness of coursework and final examinations and their responses are summarized in table 1. 


\begin{tabular}{|c|c|c|}
\hline Response & F & \% \\
\hline coursework is fairer than final exam & 67 & 19.9 \\
\hline final exam is fairer than coursework & 114 & 33.9 \\
\hline both have the same degree of fairness & 155 & 46.1 \\
\hline
\end{tabular}

Table 1: Students' Responses on Fairness of

Coursework and Final Examinations

Results in table 1 show that 155 (46.1\%) of students perceived both final examinations and coursework to have the same degree of fairness, $114(33.9 \%)$ of them perceived final examinations to be fairer than coursework and 67 (19.9\%) perceived coursework to be fairer than final examinations. These results imply that students do perceive the fairness of coursework and final examinations differently but most of them consider both forms of assessment to have the same degree of fairness. Maintaining fairness in both forms of assessment is a good move towards ensuring validity in assessment as argued by Linn and Gronlund (2000) that fairness should be maintained in all assessment activities.

However, on comparing fairness in the two forms of assessment, final examinations seemed to be fairer than coursework. This means that more students considered final examinations to be fairer than coursework. Considering fairness to be an indicator of validity, it can also be inferred that final examinations results are perceived to be more valid than coursework results. Moderation of final examinations and organized invigilation during final examinations may be among the reasons for the final examination to be considered being fairer. Less participation of students in group activities, having no policy on the development and implementation of coursework on the other hand are among the reasons for coursework being perceived as being less fair.

Cheating in continuous assessments has been identified by Bachore (2016) and Domeova \& Jindrova (2013) to be the most student-related factor for unfairness in coursework. In addition to the student-related factors, lecturer's autonomy in the process of developing, implementing and evaluating continuous assessments cannot be overlooked. For instance, it was found that lecturers do decide on the kind and number of assessment tasks to give for students' coursework. This autonomy with no proper monitoring may lead to unfair practices in assessment. This is because a lecturer may decide only to have a test from one topic or give only one task for student's coursework. This may be unfair as not all the contents taught are tested.

The researchers also were interested to find out what students perceived to be the general fairness of the whole process of assessment in universities. Students were requested to rate and their responses are summarized in table 2

\begin{tabular}{|c|c|c|c|}
\hline Responses & f & \% & General Mean \\
\hline very fair & 50 & 14.9 & \\
\hline fair & 152 & 45.2 & \\
\hline somehow fair & 109 & 32.4 & 3.67 \\
\hline less fair & 20 & 6.0 & \\
\hline not fair & 5 & 1.5 & \\
\hline
\end{tabular}

Table 2: Students Responses on General Farness of Assessments

Results in table 2 show that $152(45.2 \%), 109$ (32.4\%), $50(14.9 \%), 20(6.0 \%)$ and $5(1.15 \%)$ of students commented the whole process of assessment as being fair, somehow fair, very fair, less fair and not fair respectively. This implies that students have varying perceptions on the fairness of assessments conducted in universities whereas most of them perceive the procedure to be fair. However, few students (14.9\%) perceived the procedure to be very fair while a large number of them (109) commented on being somehow fair. Given this small number of students who indicated the assessment to be very fair and the large percent of those who opted for somehow fair, it is seen that students are suspicious about the fairness of assessments used in universities.

Considering the general perception mean score (3.76), it is also seen that students are not satisfied with how assessment is conducted in universities. This is because the scale used to measure their level of satisfaction ranged from 1 to 5 whereby, 1 stood for not satisfied at all and 5 represented much satisfied. Therefore, the value of 3.76 leads to a conclusion that; students are not much satisfied with the whole process of assessment. This low level of satisfaction as reported by students was also found in Indonesia by Abidin (2015) who revealed students to be less satisfied with the quality of teaching and learning process of which assessment makes part.

\subsection{Occurrence of Unfair Practices in Assessments}

Given this low level of satisfaction, the researcher further asked students to indicate the occurrence of cases which they considered to be unfair. Students were requested to rate the occurrence of such practices (1 to 5) whereby 1 stood for not evidenced and 5 represented much evidenced, their responses are summarized in table 3. 


\begin{tabular}{|c|c|c|c|c|c|c|c|c|c|c|}
\hline \multirow[t]{2}{*}{ Cases } & \multicolumn{2}{|c|}{5} & \multicolumn{2}{|c|}{4} & \multicolumn{2}{|c|}{3} & \multicolumn{2}{|c|}{2} & \multicolumn{2}{|c|}{1} \\
\hline & $\mathrm{f}$ & $\%$ & $\mathrm{f}$ & $\%$ & $f$ & $\%$ & $\mathrm{f}$ & $\%$ & $\mathrm{f}$ & $\%$ \\
\hline $\begin{array}{c}\text { not all students participate in group activities } \\
\text { though equal marks are awarded }\end{array}$ & 82 & 24.4 & 39 & 11.6 & 67 & 19.9 & 54 & 16.1 & 94 & 28.0 \\
\hline $\begin{array}{l}\text { using technical language in tests that is not well } \\
\text { understood by learners }\end{array}$ & 78 & 23.2 & 66 & 19.6 & 60 & 17.9 & 52 & 15.5 & 80 & 23.8 \\
\hline $\begin{array}{l}\text { students do assignment tasks for other students } \\
\text { (friends or being paid for) }\end{array}$ & 73 & 21.7 & 36 & 10.7 & 48 & 14.3 & 59 & 17.6 & 120 & 35.7 \\
\hline poor marking of scripts & 70 & 20.8 & 50 & 14.9 & 60 & 17.9 & 48 & 14.3 & 108 & 32.1 \\
\hline having ambiguous terminologies in the questions & 61 & 18.2 & 62 & 18.5 & 69 & 20.5 & 61 & 18.2 & 83 & 24.7 \\
\hline not being careful while recording students' marks & 58 & 17.3 & 46 & 13.7 & 52 & 15.5 & 53 & 15.8 & 127 & 37.8 \\
\hline $\begin{array}{c}\text { emphasizing on other factors (hand writing and } \\
\text { punctuation) instead of responses }\end{array}$ & 54 & 16.1 & 67 & 19.9 & 57 & 17.0 & 60 & 17.9 & 98 & 29.2 \\
\hline $\begin{array}{l}\text { students enter with unauthorized materials in } \\
\text { tests }\end{array}$ & 52 & 15.5 & 39 & 11.6 & 40 & 11.9 & 54 & 16.1 & 151 & 44.9 \\
\hline students do cheat during examinations & 51 & 15.2 & 34 & 10.1 & 57 & 17.0 & 63 & 18.8 & 131 & 39.0 \\
\hline $\begin{array}{l}\text { students do submit other peoples' works as their } \\
\text { own works }\end{array}$ & 51 & 15.2 & 31 & 9.2 & 55 & 16.4 & 51 & 15.2 & 148 & 44.0 \\
\hline favoring some students while marking & 44 & 13.1 & 52 & 15.5 & 49 & 14.6 & 49 & 14.6 & 142 & 42.3 \\
\hline skipping some questions while marking & 43 & 12.8 & 40 & 11.9 & 64 & 19.0 & 53 & 15.8 & 136 & 40.5 \\
\hline examinations not covering the contents & 43 & 12.8 & 43 & 12.8 & 51 & 15.2 & 47 & 14.0 & 152 & 45.2 \\
\hline $\begin{array}{c}\text { questions not being relevant to the course } \\
\text { objectives }\end{array}$ & 43 & 12.8 & 32 & 9.5 & 45 & 13.4 & 57 & 17.0 & 159 & 47.3 \\
\hline questions being out of what has been taught & 41 & 12.2 & 40 & 11.9 & 47 & 14.0 & 51 & 15.2 & 157 & 46.7 \\
\hline
\end{tabular}

Table 3: Students' Responses on Occurrence of Unfair Practices in Assessment

Results in table 3 show that failure of all students to participate in group assignments was indicated to be very common by $82(24.4 \%)$ of students. This was the factor with the highest number of students indicating it as being very common. Therefore, it implies that students do not consider the assessment procedure to be fair because they experience some students who do not participate in group assignments though equal marks are given for all group members. Less participation of students in group activities does not only affect fairness but also the validity of the obtained results. This may be one of the reasons for lecturers preferring to use individual assignments over group assignments. Despite lecturers and students being suspicious about the quality of group assignments, this form of assessment remains to be the most used one in universities (Lyamtane, 2013; Bentley \& Warwick, 2013). Therefore, to increase fairness of group assignments, lecturers need to develop mechanisms that will ensure maximum participation of students in group activities.

The use of technical language that is not well understood by learners in assessment tasks was indicated to be much evidenced in universities by 78 (23.2\%) of students. This implies that a good number of students do consider assessment tasks not being fair due to the use of technical language and terminologies that they do not readily understand. The use of technical language is considered as a limiting factor for students to demonstrate their best performance. This is why Jones (2005) asserted that the language and terminologies used in assessment should be appropriate that can be understood by learners. A similar conclusion was made by Kaminskiene and Stasiunaitiene (2013) that university students do find it difficult to work with assessment tasks having technical terminologies. Therefore, it is important for lecturers to use a language that is clear to students in the view of improving both fairness and validity of assessments in universities. Cheating in examinations and submitting other peoples' works by students as their own works were also indicated to be common in universities by $51(15.2 \%)$ of students. The results imply that cheating during assessments has not been well controlled in universities since out of one hundred students; fifteen of them do experience the phenomenon. This percentage is not small to be ignored but can significantly affect the validity of obtained results. The phenomenon of cheating in universities was found to be even more prominent in Ethiopia by Bachore (2016) who reported almost half of the lecturers and students at Hawassa University had experienced cheating. In Czech Republic the case is even more serious as reported by Domeova \& Jindrova (2013) who found most of the students trying to reach good grades without hard work but through cheating. It is important therefore for universities across the world to advice and put in implementation appropriate mechanisms to minimize or eliminate cheating in assessments as the phenomenon is common and has a significant effect on the validity of results obtained.

Poor marking and recording of scores were also identified as being common cases in universities by 70 (20.8\%) and $58(17.3 \%)$ of students respectively. These results imply that, in universities in Tanzania, there are some lecturers who are considered by their students as not taking the marking process seriously. This was made more evident when 44 (13.1\%) of students indicated the phenomenon of lecturers favoring some students in assessment tasks to be common in universities. When students are treated differently in assessment tasks, the assessment process becomes unfair (Linn \& Gronlund, 2009). Lack of assessment skills among lecturers together with large numbers of students taking education courses might be the reasons for lecturers not to take the marking process seriously. 
A small number of students (12.2\%) indicated the presence of questions that are out of what has been taught to be much evidenced in assessment tasks in universities. This means that there are cases of lecturers setting questions that are not in the syllabus, the content covered or even being relevant to the course objectives. The inclusion of questions that are neither according to the level of the learners or the course objectives makes the assessment procedure unfair. This is because students may not have been prepared for something that they had not expected. Similar findings were found in Finland by Raisanen et al (2016) who reported lecturers to be assessing different level of understanding than what was intended. Testing abilities that are different from the intended ones makes the assessment procedure fail to achieve its ultimate purpose of determining the extent to which learning is either taking place (formative) or has taken place (summative).

The researcher further quantified the factors that affect assessment fairness to generate mean scores. This was done so as to determine which factors do affect assessment fairness to a great extent. The factors were categorized into three major categories namely lecturer related, assessment tools related and assessment conditions related factors. The mean scores for each factor $(\bar{x})$ and for each category $(\mu)$ were both computed. Table 4 presents the results of analysis whereby the first five factors makes the lecturer related category, the second five presents the assessment tools category and the last five factors makes up the assessment conditions category.

\begin{tabular}{|c|c|c|c|}
\hline SN & Source of Errors & $\overline{\mathbf{x}}$ & $\mathbf{\mu}$ \\
\hline 1 & poor marking of scripts & 2.78 & \\
\hline 2 & favoring some students while marking & 2.43 & \\
\hline 3 & emphasizing on other factors instead of responses & 2.76 & 2.59 \\
\hline 4 & not being careful while recording students' marks & 2.57 & \\
\hline 5 & skipping some questions while marking & 2.41 & \\
\hline 6 & using technical language in tests that is not well understood by learners & 3.03 & \\
\hline 7 & having ambiguous terminologies in the questions & 2.87 & \\
\hline 8 & examinations not covering the contents & 2.34 & 2.55 \\
\hline 9 & questions being out of what has been taught & 2.28 & \\
\hline 10 & questions not being relevant to the course objectives & 2.24 & \\
\hline 11 & students do cheat during examinations & 2.44 & \\
\hline 12 & students do submit other peoples' works as their own works & 2.36 & \\
\hline 13 & not all students participate in group activities & 2.88 & 2.54 \\
\hline 14 & students do assignment tasks for other students & 2.66 & \\
\hline 15 & students enter with unauthorized materials in tests & 2.37 & \\
\hline
\end{tabular}

Table 4: Mean Scores for Sources of Errors

Results in table 4 show that the lecturer related category had a higher mean score (2.59) than the assessment tool and condition categories which had mean scores of 2.55 and 2.54 respectively. To test whether such difference was significant, one-way ANOVA was run at 95\% confidence level and the results of hypothesis testing are summarized in table 5.

- Null Hypothesis 1: There is no significant difference in the error mean scores contributed by lecturer, tool and condition related factors.

\begin{tabular}{|c|c|c|c|c|c|}
\hline Error & Sum of Squares & df & Mean Square & F & Sig. \\
\hline Between Groups & .006 & 2 & .003 & .044 & .957 \\
\hline Within Groups & .871 & 12 & .073 & & \\
\hline Total & .877 & 14 & & & \\
\hline
\end{tabular}

Table 5: ANOVA Summary Table for Null Hypothesis 1

Results of hypothesis testing show that $F(2,12)=0.044$ and $p$-value $=0.957$. Since the $p$-value $(0.957)$ is greater than the significance level $(0.05)$ the null hypothesis in not rejected. Failing to reject the null hypothesis means that there is no significant difference in the error mean scoresattributed by lecturer, tools and condition related factors. This implies that both the three categories of errors do affect the fairness of assessments in universities at almost equal rates. Therefore, to in making the assessment procedure in universities fair, there needs to be initiatives on ensuring that lecturers are equipped with assessment skills so that they can develop and implemented assessment processes in a way that will maximize fairness.

Though the results of hypothesis testing show no difference in the error mean scores, much emphasis should be put on the lecturer category when looking on best means of ensuring fairness in assessment. This is because, unlike the 
generalizability theory which assumes that sources of errors are dependent of one another, assessment conditions and the effectiveness of the tools used all depend on the competence of the lecturer. For example, if a lecturer has no adequate skills in test development and administration, the quality of test developed together with how it is administered may all be affected. Therefore, it is important for university lecturers to update themselves on educational assessment for them to be in a better place of developing and administering assessment tasks effectively and hence the assessment procedure will be considered to be fair.

As lecturer related factors was found to have a mean score higher than the other factors, the researchers quantified students' responses on the extent to which lecturers favor students during marking, the mean score perception of students in public universities (2.38) was found to be higher than that of students from private universities (2.01). To determine whether the observed difference was significant, an independent sample t-test was run taking 0.05 as the significance level. The results of analysis are presented in table 6.

- Null hypothesis 2: There is no significant difference in the perception mean scores of students in private and public universities on lecturers' tendency to favor students in marking.

\begin{tabular}{|c|c|c|c|c|c|c|c|c|c|c|}
\hline & \multicolumn{2}{|c|}{$\begin{array}{c}\text { Levene's Test for } \\
\text { Equality of Variances }\end{array}$} & \multicolumn{7}{|c|}{ t-Test for Equality of Means } \\
\hline & & \multirow[t]{2}{*}{$\mathrm{F}$} & \multirow[t]{2}{*}{ Sig. } & \multirow[t]{2}{*}{$\mathrm{t}$} & \multirow[t]{2}{*}{$\mathrm{df}$} & \multirow[t]{2}{*}{$\begin{array}{c}\text { Sig. } \\
\text { (2-tailed) }\end{array}$} & \multirow[t]{2}{*}{$\begin{array}{c}\text { Mean } \\
\text { Difference }\end{array}$} & \multirow[t]{2}{*}{$\begin{array}{l}\text { Std. Error } \\
\text { Difference }\end{array}$} & \multicolumn{2}{|c|}{$\begin{array}{l}\text { 95\% Confidence } \\
\text { Interval of the } \\
\text { Difference }\end{array}$} \\
\hline & & & & & & & & & Lower & Upper \\
\hline \multirow{2}{*}{$\begin{array}{l}\text { Lecturers } \\
\text { do favor } \\
\text { some } \\
\text { student } \\
\text { while } \\
\text { marking }\end{array}$} & $\begin{array}{c}\text { Equal } \\
\text { variances } \\
\text { assumed }\end{array}$ & 1.022 & .313 & 2.888 & 334 & .004 & .370 & .128 & .118 & .622 \\
\hline & $\begin{array}{c}\text { Equal } \\
\text { variances } \\
\text { not } \\
\text { assumed }\end{array}$ & & & 2.884 & 302.6 & .004 & .370 & .128 & .118 & .622 \\
\hline
\end{tabular}

Table 6: T-Test for Null Hypothesis 2

Results of hypothesis testing show that $\mathrm{t}(334)=2.888, \mathrm{p}=0.004$. Since $\mathrm{p}$-value $(0.004)$ is less than significance level (0.05), the null hypothesis was rejected. Rejecting the null hypothesis means that there is a significant difference in the mean score perception of students in public and private universities on the extent to which lecturers favor students during marking. This implies that lecturers in public universities are perceived to be favoring their students in the marking process more compared to their counterparts from private universities.

Similar findings were obtained by Mazumder (2014) who compared the quality of public and private Universities in Bangladesh and USA. Public Universities were found as being reluctant to update their teaching methods course contents and assessment strategies. On the other side private universities were found to be striving to improve their curricular as well as teaching and assessment methods. This shows that lecturers in public universities do not take the assessment process seriously as what their counter parts in private universities do. This is also evidenced through researcher own experience whereby he once experienced education stakeholders complaining about the credibility of assessment results especially for some public Universities where some graduates with good results were reported not being able to defend such good grades in their places of work.

The tendency of lectures to favor students and give them high scores may be a reason for having a poor linkage between academic and industry whereby University graduates are found not to fit in their work places (respective fields) beside having good grades as reported by Gasper (2013), Cai (2014), Oye, Banji \&Jumoke (2015) Nyantamila (2016)and Istoroyekti (2016). To make the results of assessment valid meaningful and reflecting graduates ability lectured therefore need to be fair in the process of marking and avoid giving scores on personal biases. For places where the tendency of favoring is too high, we suggest the use of panel marking so as to remove the chance of an individual lecturer dealing with all the papers.

\section{Conclusions}

University students are not satisfied with the general practice of assessments. Their level of satisfaction concerning fairness of the assessment process is low. Comparing the two forms of assessments (formative and summative), summative assessment is considered to be a little bit higher than summative assessment. This is because the mean perception of students on the fairness of the two forms of assessment was higher in summative assessment than that of formative assessment though the difference was not found to be significant though statistical analysis. Moderation of summative examinations and organized invigilation process are the reasons for improved fairness in summative examinations.

The general perception mean score was 3.67 which lie between being fair and somehow fair. Having some students not participating in group activities, the use of technical language in assessment tasks and poor marking of student's scripts were identified as being the major factors that contribute to an assessment procedure to be regarded by students as not being fair. The error mean score for lecturer related factors was found to be higher than the condition and assessment tool related factors. However, results of hypothesis test showed no significant difference in the three mean scores indicating that they both cause errors at a similar extent. The tendency of lecturers favoring students is higher in 
public universities than in private ones. The mean score on favoring was higher in public than in private and through statistical analysis; the difference was found to be significant.

\section{Recommendations}

Lecturers need to be objective in the process of assessment so as to improve fairness in assessment. This is because in the study lecturer - related factors were found contributing more on unfairness in assessment as compared to the tools and conditions related factors as perceived by students. Lecturers were reported to be favoring some students and the general process of marking tests was rated poor. Moreover, some lecturers were reported to include questions that are different from the course objectives. Universities also need to have mechanisms of monitoring the continuous assessments practices so as to ensure fairness in the whole process. Continuous assessment tasks also need to be moderated so as to minimize the errors that may lead to unfair interpretation.

\section{References}

i. Abidin, M. (2015). Higher Education Quality: Perception Differences among Internal and External Stakeholders. International Education Studies, 8(12).

ii. Aiken, L. R. (2000). Psychological testing and assessment (10th ed). Boston: Allyn and Bacon.

iii. Bachore, M. M. (2016). The Nature, Causes and Practices of Academic Dishonesty/ Cheating in Higher Education: The Case of Hawassa University. Journal of Education and Practice, 7(19).

iv. Cai. (2014). Enhancing Overseas Chinese Graduate Employability: The Case of Chinese Graduates with Finnish Academic Qualifications. Frontiers of Education in China, 9(3), 377-402

v. Domeova, L., \&Jindrova, A. (2013). Unethical Behavior of the Students of the Czech University of Life Sciences. International Education Studies, 6(11).

vi. Gasper, M. (2013). Academia-Industry-Government Linkages in Tanzania: Trends, Challenges and Prospects. Educational Research and Reviews, 8(21), 2093-2100.

vii. Gronlund, N. E., \& Waugh, C. K. (2009). Assessment of student achievement (9th ed). Upper Saddle River, N.J: Pearson.

viii. Linn, R. L., Gronlund, N. E., \& Davis, K. M. (2000). Measurement and assessment in teaching (8th ed). Upper Saddle River, N.J: Merrill.

ix. Lord, F. M., \&Novick, M. R. (1968). Statistical theories of mental test scores. Reading, MA: Addison-Wesley.

x. Lyamtane, E. (2013). Assessment of the Implementation of Inter-University Council for East Africa Quality Assurance Guidelines in Faculties of Education Of Chartered Universities In Tanzania. Catholic University of Eastern Africa, Nairobi.

xi. Mazumder, Q. H. (2014). Analysis of Quality in Public and Private Universities in Bangladesh and USA, 3(2), 10.

xii. Oyebanji, A., \&Jumoke, O. (2015).Employability of Nigerian Graduates, the Role of Stakeholders. African Higher Education Review, 9(1-2), 87-94.

xiii. Pereira, D., Barros, A., \& Flores, M. A. (2017). Perceptions of Portuguese Undergraduate Students about Assessment: A Study in Five Public Universities. Educational Studies, 43(4), 442-463.

xiv. Popham, W. J. (2008). Classroom assessment: what teachers need to know (5th ed). Boston: Pearson/ Allyn and Bacon.

xv. Raisanen, M., Tuononen, T., Postareff, L., Hailikari, T., \& Virtanen, V. (2016).Students' and Teacher's Experiences of the Validity and Reliability of Assessment in a Bioscience Course. Higher Education Studies, 6(4), 181-189. 